\title{
Association of Bax and Bcl-2 Functional Polymorphisms and Protein Levels with Posttraumatic Stress Disorder
}

\author{
Diana Avetyan ${ }^{1}$, Arsen Arakelyan 1,2, Gohar Mkrtchyan ${ }^{1 *}$ \\ ${ }^{1}$ Laboratory of Human Genomics and Immunomics, Institute of Molecular Biology, Armenian National Academy of Sciences, \\ Yerevan, Armenia \\ ${ }^{2}$ Group of Bioinformatics, Institute of Molecular Biology, Armenian National Academy of Sciences, Yerevan, Armenia \\ Email: *g_mkrtchyan@mb.sci.am
}

How to cite this paper: Avetyan, D., Arakelyan, A. and Mkrtchyan, G. (2018) Association of Bax and Bcl-2 Functional Polymorphisms and Protein Levels with Posttraumatic Stress Disorder. Journal of Biosciences and Medicines, 6, 23-32.

https://doi.org/10.4236/jbm.2018.62003

Received: January 18, 2018

Accepted: February 23, 2018

Published: February 26, 2018

Copyright (C) 2018 by authors and Scientific Research Publishing Inc. This work is licensed under the Creative Commons Attribution International License (CC BY 4.0).

http://creativecommons.org/licenses/by/4.0/

\begin{abstract}
Background: Posttraumatic stress disorder (PTSD) is an anxiety disease influenced by both environmental and genetic factors, which affects a patient's quality of life and social stability. Recent studies have shown that the pathogenesis of PTSD is associated with apoptosis; however, the molecular mechanisms that cause such damage are not well-understood. Also it is unclear whether these pathologic alterations are genetically determined or caused by other factors. The aim of this study was to investigate the genetic association of functional polymorphisms in genes coding for apoptosis-related Bcl-2 and Bax proteins with PTSD as well as proteins levels in the blood of affected subjects. Methods: The study groups consisted of 200 combat veterans with PTSD and an equal number of healthy subjects with no family- or past-history of any psychiatric disorders. Bax and Bcl-2 proteins levels in blood were measured by ELISA. DNA samples were genotyped for SNPs using PCR-SSP. Results: According to our results, PTSD patients are characterized by increased levels of apoptotic proteins and the imbalance in the $\mathrm{Bax} / \mathrm{Bcl}-2$ ratio compared to healthy subjects. Our results also demonstrate that $\mathrm{rs} 956572^{\star} \mathrm{A}$ minor allele of the $B C L 2$ gene was overrepresented in patients with PTSD compared to healthy subjects. Conclusions: The results implicate Bcl-2 and Bax in pathogenesis of PTSD on genetic and protein levels, though further studies on enlarged cohort and in different populations are required.
\end{abstract}

\section{Keywords}

Posttraumatic Stress Disorder, Apoptosis, BCL2, BAX, Single Nucleotide Polymorphisms 


\section{Introduction}

Posttraumatic stress disorder (PTSD; ICD-10-CM codes: F43.1; DSM-V code: 309.81) is an anxiety disease that develops as a result of a serious psychological trauma following an event of a threat of death or major injury [1] [2]. The diagnosis of PTSD is based on the symptoms causing clinically significant suffering or impairment in social and/or professional dysfunction for a period of up to six months [3] [4].

Recently the number of risk factors contributing to the development of PTSD has dramatically increased worldwide. Therefore, one of the most common problems of health care nowadays is the development of efficient prognostic strategies and methods of early diagnostics and treatment of PTSD. Epidemiological, clinical, and experimental research data suggest that both environmental and genetic factors are involved in the pathogenesis of PTSD. Several studies suggest that PTSD is a complex disorder with polygenic inheritance [5] [6] [7].

PTSD is characterized by neuroendocrine abnormalities, particularly with dysfunction of the hypothalamic-pituitary-adrenal (HPA) axis, which is expressed by low levels of cortisol and adrenocorticotropic hormone (ACTH) in plasma [8]. Many studies showed that the amygdala, hippocampus, and medial prefrontal cortex (mPFC) are responsible for the occurrence of PTSD. In particular, mPFC is controlling stress and fear responses of amygdala and hippocampus [9]. Recent neuro-imaging studies have shown that the volume of hippocampus decreases in PTSD patients compared to healthy subjects [10]. This atrophy can be associated with apoptosis, but these molecular mechanisms are yet to be understood [11].

Apoptosis is a genetically controlled process of the cell death that takes place in response to various intrinsic and environmental factors; it results in orderly removal of unorthodox cells [12]. Studies have identified various pathways of apoptosis based on different physiological and pathological stimuli. Among them are the intrinsic mitochondrial and extrinsic death receptor pathways which eventually lead to the activation of caspase-3, which in its turn causes protein degradation and damage to cellular integrity [13]. Apoptosis plays an important role in the pathogenesis of neurodegenerative diseases [14]. Studies also showed, that in acute and chronic stress, activation of intrinsic mitochondrial pathway due to stress and subsequent morphological variations results in atrophy in different areas of brain, especially in hippocampus [15] [16]. The B-cell lymphoma 2 (Bcl-2) family members play an important role in the controlling of apoptosis. It includes pro-apoptotic proteins as BCL2-associated X protein (Bax) and anti-apoptotic protein as Bcl-2, which are involved in a large variety of cellular activities [17]. Recent in vitro studies also showed that high levels of Bax can promote apoptosis, whereas increased levels of Bcl-2 inhibit apoptosis [18]. Therefore, the imbalance of $\mathrm{Bax} / \mathrm{Bcl}-2$ ratio is an important measure for apoptosis [19]. The study by Li et al. has shown that one of the reasons of PTSD development in rats was the increase of the Bcl-2 and Bax expression, and the imbalance in the Bcl-2/Bax ratio. This can be one of the mechan- 
isms causing neuronal apoptosis in MPFC [20].

The aim of this study was the investigation of the potential role of anti-apoptotic protein $\mathrm{Bcl}-2$ and pro-apoptotic proteins Bax in the pathogenesis of PTSD on the levels of functional polymorphism in coding genes and protein abundance.

\section{Materials and Methods}

\subsection{Study Subjects}

Study groups consisted of 200 combat veterans with PTSD (mean age: $\mathrm{M} \pm \mathrm{SD}=$ $54.52 \pm 11.0$ years) and an equal number of healthy subjects (HS) (mean age: $\mathrm{M}$ $\pm \mathrm{SD}=43.6 \pm 9.1$ years) with no family or past history of any psychological disorders. Clinical diagnosis was made according to the Clinician Administered PTSD Scale (CAPS) [4]. All subjects were Armenian nationality born and living in Armenia and Artsakh. Both, the informed consents from all study subjects and the approval of the Ethics Committee of the Institute of Molecular Biology of NAS RA (IRB \#00004079) were received for these studies.

\subsection{Blood Sampling and Genomic DNA Extraction}

About $5 \mathrm{ml}$ of peripheral venous blood was collected from each study subject and transferred to EDTA-containing tubes. Genomic DNA was isolated from the fresh blood samples according to Miller's salting-out procedure [21] modification where proteinase $\mathrm{K}$ was omitted and a chloroform extraction phase was added and stored at $-30^{\circ} \mathrm{C}$ until further use.

\subsection{Determination of Bax and Bcl-2 Levels by ELISA}

Bax and Bcl-2 protein levels were determined with an ELISA Kit (USCN Life Science Inc., Wuhan, China) according to the manufacturer's instructions.

\subsection{Primer Design}

DNA samples were genotyped for $B A X$ rs1057369, $B C L 2$ rs956572 and rs1801018 functional SNPs (Table 1).

All primers for PCR-SSP were designed using the genomic sequences in the GenBank nucleotide sequence database (https://www.ncbi.nlm.nih.gov/genbank/) and are indicated in Table 2.

Table 1. Brief characteristics of selected genes and SNPs.

\begin{tabular}{ccccccc}
\hline \multicolumn{3}{c}{ Gene } & \multicolumn{4}{c}{ SNP } \\
\hline Name & ID & Location & ID & Substitution $^{\mathrm{a}}$ & Position & Location (type) \\
\hline BAX & 581 & $19 \mathrm{q} 13.33$ & rs1057369 & $\mathrm{A}>\mathrm{G}$ & 49464866 & Intronic \\
& & & $\mathrm{rs} 956572$ & $\mathrm{G}>\mathrm{A}$ & 60820571 & Intronic \\
BCL2 & 596 & \multirow{2}{*}{$18 \mathrm{q} 21.33$} & $\mathrm{rs} 1801018$ & $\mathrm{~A}>\mathrm{G}$ & 60985879 & exonic (synonymous) \\
& & & & & & \\
\hline
\end{tabular}

a. forward strand. 
Table 2. Primers designed for the selected SNPs.

\begin{tabular}{cl}
\hline \multicolumn{1}{c}{ SNP } & \multicolumn{1}{c}{ Nucleotide sequence of primers } \\
\hline \multirow{2}{*}{ rs1057369 } & standard allele: 5'-ATCTTCTTCCAGATGGTGAGT \\
& minor allele: 5'-ATCTTCTTCCAGATGGTGAGC \\
& constant: 5'-TTACAGGTGTGAGCCACCATG \\
& standard allele: 5'-AGAGGGAGTCATGACTGAATC \\
& minor allele: 5'-AGAGGGAGTCATGACTGAATT \\
rs956572 & constant: 5'-CAGATCTGTGCTTGAACCTCA \\
& standard allele: 5'ATCTCCCGGTTATCGTACCCT \\
& minor allele: 5'-ATCTCCCGGTTATCGTACCCC \\
rs1801018 & constant: 5'-GATCCGAAAGGAATTGGAATA \\
\hline
\end{tabular}

\subsection{Polymerase Chain Reaction with Sequence Specific Primers}

Genotyping was carried out by polymerase chain reaction with sequence-specific primers (PCR-SSP) according to protocol developed in Bunce et al. [22]. The presence/absence of allele-specific amplicons in the PCR products was visualized in 2\% agarose gel stained with Ethidium Bromide fluorescent dye using DNA molecular weight markers as a reference. To check the reproducibility of results, randomly selected DNA samples ( $10 \%$ of total) were genotyped twice.

\subsection{Data Analysis}

The distributions of genotypes for all investigated SNPs were checked for correspondence to the Hardy-Weinberg ( $\mathrm{H}-\mathrm{W})$ equilibrium. In order to find potential relevance of the selected SNPs to PTSD, their genotype and allele frequencies and minor allele carriage rates in patients and HS were compared. The significance of differences in genotype and allele frequencies and minor allele carriage between patients and HS was determined using Pearson's Chi-square test. P-values less than 0.05 were considered statistically significant. P-values adjusted by Bonferroni multiple comparison correction is further indicated as $\mathrm{p}_{\text {corrected }}$, and those not adjusted as $\mathrm{p}_{\text {nominal }}$.

\section{Results}

\subsection{Estimation of Bax and Bcl-2 Levels by ELISA}

We evaluated Bax and Bcl-2 plasma levels of $39 \mathrm{HS}$ and 40 patients with PTSD. The study indicates that $\mathrm{Bax}$ and $\mathrm{Bcl}-2$ protein levels in the blood of patients with PTSD were increased compared to HS (Figure 1 and Figure 2).

The mean levels of Bax and Bcl-2 proteins, respectively, were significantly 1.6 $(\mathrm{p}=0.002)$ and $2.1(\mathrm{p}=0.0002)$ times higher among patients than among HS.

Bax is a pro-apoptotic, while Bcl-2 is an anti-apoptotic member of the Bcl-2 protein family. The relative amount or balance between the pro- and anti-apoptotic proteins influences the receptiveness to apoptosis.

The analysis demonstrated (Figure 3) that PTSD patients have lower Bax/Bcl-2 


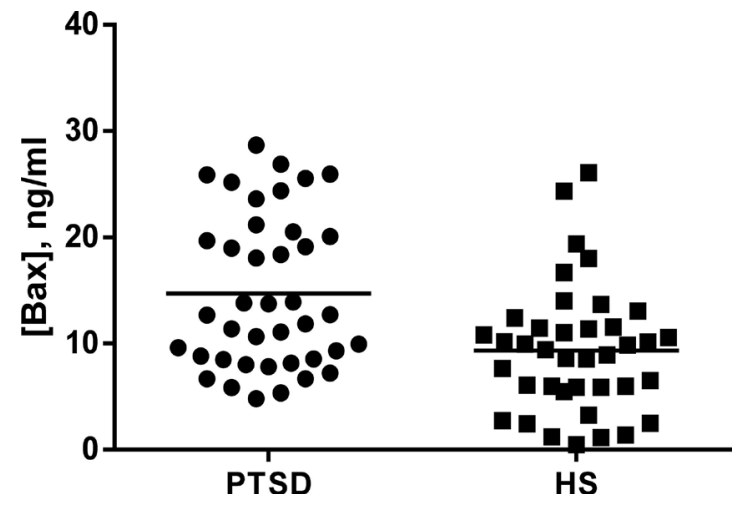

Figure 1. Bax levels in PTSD patients and HS.

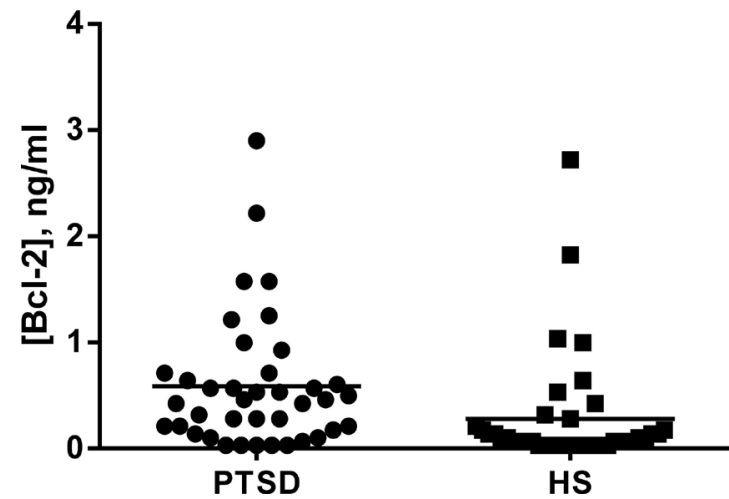

Figure 2. Bcl-2 levels in PTSD patients and HS.

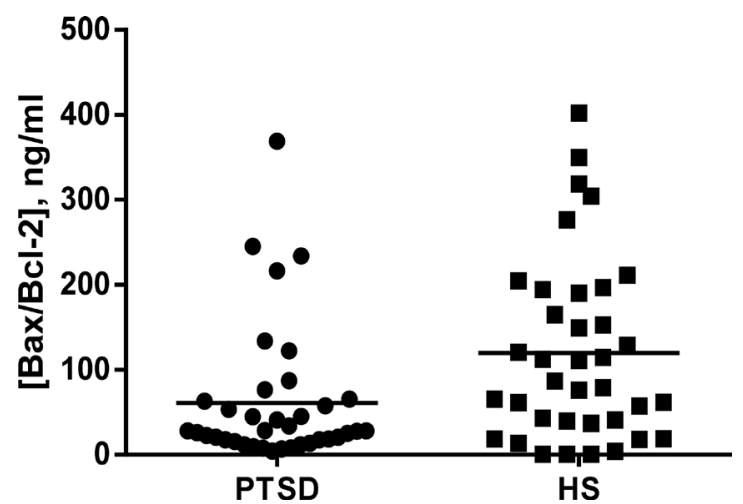

Figure 3. Bax/Bcl-2 ratio in PTSD patients and HS.

ratio as compared with HS (1.96 time; $\mathrm{p}=0.008)$.

\subsection{Genotyping of $B A X$ rs1057369 and $B C L 2$ rs956572, rs1801018 SNPs}

Distribution of $B C L 2$ rs956572, rs1801018 and $B A X$ rs1057369 variants in study groups is shown in Table 3. According to the data obtained, the rs956572*A minor allele of the $B C L 2$ gene was overrepresented in patients with PTSD compared to HS ( $\mathrm{p}_{\text {nominal }}=6.02 \mathrm{E}-11$; OR $=2.59 ; 95 \% \mathrm{CI}$ : $1.94-3.44$ ). In addition, the carriers of this allele were more in the group of patients compared to HS ( $\mathrm{p}_{\text {nominal }}$ $=4.11 \mathrm{E}-7 ;$ OR $=3.53 ; 95 \% \mathrm{CI}: 2.14-5.81$ ). 
Table 3. Distribution of genotypes, alleles and carriage of minor alleles of $B A X$ and $B C L 2$ polymorphisms in patients with PTSD and HS.

\begin{tabular}{|c|c|c|c|c|}
\hline Gene (SNP) & & $\operatorname{PTSD}(\mathrm{n}=200)$ & $\mathrm{HS}(\mathrm{n}=200)$ & $\mathrm{p}_{\text {corrected }}$ \\
\hline \multicolumn{5}{|l|}{$B C L 2$ rs956572 } \\
\hline \multirow{3}{*}{ Genotypes } & GG & $27(0.135)$ & $71(0.355)$ & \\
\hline & GA & $89(0.445)$ & $94(0.47)$ & \\
\hline & $\mathrm{AA}$ & $84(0.42)$ & $35(0.175)$ & \\
\hline \multirow{2}{*}{ Alleles } & G & $143(0.36)$ & $236(0.59)$ & \\
\hline & A & $257(0.64)$ & $164(0.41)$ & $1.20 \mathrm{E}-10 \mathrm{a}$ \\
\hline Carriage & A & $173(0.87)$ & $129(0.65)$ & $8.22 \mathrm{E}-07 \mathrm{~b}$ \\
\hline \multicolumn{5}{|l|}{$B C L 2$ rs1801018 } \\
\hline \multirow{3}{*}{ Genotypes } & $\mathrm{AA}$ & $78(0.39)$ & $42(0.21)$ & \\
\hline & AG & $83(0.415)$ & $114(0.57)$ & \\
\hline & GG & $39(0.195)$ & $44(0.22)$ & \\
\hline \multirow{2}{*}{ Alleles } & A & $239(0.6)$ & $198(0.5)$ & \\
\hline & G & $161(0.4)$ & $202(0.5)$ & $0.0072 a$ \\
\hline Carriage & G & $122(0.61)$ & $158(0.79)$ & $1.70 \mathrm{E}-04 \mathrm{~b}$ \\
\hline \multicolumn{5}{|l|}{$B A X \mathrm{rs} 1057369$} \\
\hline \multirow{3}{*}{ Genotypes } & $\mathrm{AA}$ & $32(0.16)$ & $36(0.18)$ & \\
\hline & AG & $155(0.775)$ & $106(0.53)$ & \\
\hline & GG & $13(0.065)$ & $58(0.29)$ & \\
\hline Alleles & A & $220(0.55)$ & $178(0.445)$ & 0.003 \\
\hline Carriage & G & $180(0.45)$ & $222(0.555)$ & 0.59 \\
\hline
\end{tabular}

a. $\mathrm{p}_{\text {corrected }}$ values for comparison of mutant allele frequency between PTSD patients and controls. b. $\mathrm{p}_{\text {corrected }}$ values for comparison of mutant allele carriage between PTSD patients and controls.

Further, we found that the frequency of the $\operatorname{rs} 1801018^{\star} \mathrm{G}$ minor allele of the $B C L 2$ gene was lower among patients compared to $\mathrm{HS}$ ( $\mathrm{p}_{\text {nominal }}=0.0036$; $\mathrm{OR}=$ $0.66,95 \% \mathrm{CI}: 0.5-0.87)$. Also, the carriers of the rs $1801018^{\star} \mathrm{G}$ minor allele was less frequent in patients than in $\mathrm{HS}$ ( $\mathrm{p}_{\text {nominal }}=8.6 \mathrm{E}-5$; OR $=0.42$; 95\%CI: 0.27 0.65). The rs $1057369^{\star} \mathrm{G}$ allele of the $B A X$ gene was less frequent among patients than in HS ( $\mathrm{p}_{\text {nominal }}=0.002$; OR $=0.66,95 \% \mathrm{CI}: 0.5-0.87$ ). Although there were no significant differences of carriers of $\mathrm{rs} 1057369^{\star} \mathrm{G}$ minor allele in the group of patients compared to HS ( $\left.\mathrm{p}_{\text {nominal }}=0.6 ; \mathrm{OR}=1.15,95 \% \mathrm{CI}: 0.683-1.943\right)$. After Bonferroni correction, difference in minor allele frequency between the patients and HS groups remained significant.

Thus the results of our study indicated positive association between the BCL2 gene rs956572 SNP and PTSD. There were no significant differences between selected SNPs and Bax and Bcl-2 proteins levels.

\section{Discussion}

Bcl-2 family proteins are the regulators of apoptosis; they include inhibitors and 
inducers of mitochondria-mediated cell death. In this study, we showed that both levels of pro-apoptotic Bax and anti-apoptotic Bcl-2 proteins were significantly increased in the plasma of PTSD patients. However, Bax/Bcl-2 ratio, which appears to be more informative parameter than individual protein levels [23], was decreased in PTSD patients compared to healthy subjects ( $p=0.008$ ).

The number of studies revealing the associations between apoptosis and PTSD in human subjects is limited and the mechanisms by which Bc1-2 and Bax develop their functions in PTSD are not well studied and mostly conducted on animal models. Thus, Li et al.'s study on the hippocampus of rats by using single prolong stress model, showed that apoptotic Bax, caspase-3 proteins, and the ratio of $\mathrm{Bax} / \mathrm{Bcl}-2$ in all stressed groups under 1 month were significantly increased, and the anti-apoptotic $\mathrm{Bcl}-2$ protein was significantly decreased as compared with the healthy group [20] [24]. Alani et al. have shown that activation of caspase- 3 in the stress groups of rats indicates that it is one of the reasons of apoptosis inducing atrophy of hippocampus, and might play important role in the pathogenesis of PTSD [25].

While there is the evidence of apoptosis contribution to brain damage in PTSD, the opposite was noticed on systemic level. Our previous study showed that the blood level of annexin-A5 was significantly lower and the levels of TNF- $\alpha$ were significantly higher in PTSD patients. This low apoptosis rate may be one of the factors responsible for development of PTSD-associated low-grade inflammation [26]. Thus, our current research suggests that the low level of $\mathrm{BAX} / \mathrm{Bcl}-2$ ratio in peripheral blood can be explained by chronic low-grade inflammatory response process in PTSD.

In the present study, we evaluated the association of SNPs of $B A X \mathrm{rs} 1057369$ (A > G; chromosome 19: 49464866; intron variant), $B C L 2$ rs956572 (G > A; chromosome 18: 60820571, intron variant) and BCL2 rs1801018 (A > G; chromosome 18: 60985879, synonymous codon) with PTSD using PCR-SSP. The $B C L 2$ rs1801018 and rs956572 SNPs have been studied in different psychiatric disorders. The rs956572 SNP was shown to be associated with the risk of developing bipolar disorder and can be modulating the expression of Bcl-2 protein, which leads to the increased cellular vulnerability to apoptosis [27]. This SNP was reported to affect the volume of gray matter in areas known to play key roles in the neurobiology of reward processes and emotion regulation, as well as in the pathophysiology of mood disorders [28]. It was demonstrated that the rs956572 SNP may modulate cognitive function and the volume of regional gray matter in non-demented elderly men, and affect language performance through its effect on the right middle temporal gyrus. The rs956572 SNP association with increased anterior cingulate cortical glutamate was demonstrated [29]. In addition, in patients with Bipolar disorder, abnormal $B C L 2$ gene expression in the AA genotype of the rs956572 SNP contributes to dysfunctional $\mathrm{Ca}^{2+}$ homeostasis [30].

Our results indicated that $\mathrm{rs} 956572^{\star} \mathrm{A}$ minor allele of the $B C L 2$ gene was 
overrepresented in patients with PTSD compared to the healthy subjects, and rs $1801018^{\star} \mathrm{G}$ minor allele of the $B C L 2$ gene was less frequent among PTSD patients compared to healthy subjects.

The genetic understanding of PTSD through candidate gene studies is premature at this point, although several genes hold promise as potential biomarkers. Identifying and understanding the genetics of PTSD will enrich our ability of diagnosis of PTSD. Profound understanding of risks in PTSD is possible through classic and convergent genomic approaches and this will lead to development of targeted treatment and prevention approaches.

\section{Limitations}

The limitation of our study is a small sample size of the subjects studied. However, all these subjects are homogeneous by their origin and traumatic event; they are Artsakh combat veterans, ethnic Armenians. Further research in other populations and ethnic groups is necessary to replicate these findings.

\section{Acknowledgements}

The authors express their gratitude to the administration and medical staff of the Stress Center of the ArtMed Medical Rehabilitation Center of the Republic of Armenia, Artsakh Scientific Center of the Republic of Artsakh and Erebouni Medical Center MH RA for selection of PTSD patients and healthy control subjects for this study.

This work made possible by a research grant from the Armenian National Science and Education Fund (ANSEF) based in New York, USA.

\section{Declaration of Interest}

The authors report no conflicts of interest.

\section{References}

[1] ICD-10-CM (2016) The International Statistical Classification of Diseases and Related Health Problems. 10th Edition, World Health Organization, Geneva.

[2] DSM-V (2013) Diagnostic and Statistical Manual of Mental Disorders by the American Psychiatric Association. 5th Edition, American Psychiatric Association Publishing.

[3] American Psychiatric Association (2013) Diagnostic and Statistical Manual of Mental Disorders. American Psychiatric Association.

[4] Blake, D.D., Weathers, F.W., Nagy, L.M., Kaloupek, D.G., Gusman, F.D., Charney, D.S. and Keane, T.M. (1995) The Development of a Clinician Administered PTSD Scale. Journal of Traumatic Stress, 8, 75-90. https://doi.org/10.1002/jts.2490080106

[5] Afifi, T.O., Asmundson, G.J., Taylor, S. and Jang K.L. (2010) The Role of Genes and Environment on Trauma Exposure and Post-Traumatic Stress Disorder Symptoms: A Review of Twin Studies. Clinical Psychology Review, 30, 101-112. https://doi.org/10.1016/j.cpr.2009.10.002

[6] Cornelis, M.C., Nugent, N.R., Amstadter, A.B. and Koenen, K.C. (2010) Genetics of 
Post-Traumatic Stress Disorder: Review and Recommendations for Genome-Wide Association Studies. Current Psychiatry Reports, 12, 313-326. https://doi.org/10.1007/s11920-010-0126-6

[7] Boyajyan, A., Avetyan, D., Hovhannisyan, L. and Mkrtchyan, G. (2015) Genetics of Posttraumatic Stress Disorder: Candidate Genes and Their Implication in the Disease-Associated Molecular Pathomechanisms. In: Durbano, F., Ed., A Fresh Look at Anxiety Disorders, InTech., London, 65-88. https://doi.org/10.5772/60443

[8] Shin, L.M., Rauch, S.L. and Pitman R.K. (2006) Amygdala, Medial Prefrontal Cortex, and Hippocampal Function in PTSD. Annals of the New York Academy of Sciences, 1071, 67-79. https://doi.org/10.1196/annals.1364.007

[9] Roozendaal, B., Griffith, Q.K., Buranday, J., De Quervain, D.J. and McGaugh, J.L. (2003) The Hippocampus Mediates Glucocorticoid Induced Impairment of Spatial Memory Retrieval: Dependence on the Basolateral Amygdale. Proceedings of the National Academy of Sciences of the United States of America, 100, 1328-1333. https://doi.org/10.1073/pnas.0337480100

[10] Bonne, O., Brandes, D., Gilboa, A., Gomori, J.M., Shenton, M.E., Pitman, R.K. and Shalev, A.Y. (2001) Longitudinal MRI Study of Hippocampal Volume in Trauma Survivors with PTSD. American Journal of Psychiatry, 158, 1248-1251. https://doi.org/10.1176/appi.ajp.158.8.1248

[11] Kitayama, N., Vaccarino, V., Kutner, M., Weiss, P. and Bremner, J.D. (2005) Magnetic Resonance Imaging [MRI] Measurement of Hippocampal Volume in Posttraumatic Stress Disorder: A Meta-Analysis. Journal of Affective Disorders, 88, 79-86. https://doi.org/10.1016/j.jad.2005.05.014

[12] Skommer, J., Wlodkowic, D. and Deptala, A. (2007) Larger than Life: Mitochondria and the Bcl-2 Family. Leukemia Research, 31, 277-286.

https://doi.org/10.1016/j.leukres.2006.06.027

[13] Guicciardi, M.E. and Gores, G.J. (2009) Life and Death by Death Receptors. THE FASEB Journal, 23, 1625-1627. https://doi.org/10.1096/fj.08-111005

[14] Waldmeier, P.C. and Tatton, W.G. (2004) Interrupting Apoptosis in Neurodegenerative Disease: Potential for Effective Therapy? Drug Discovery Today, 9, 210-208. https://doi.org/10.1016/S1359-6446(03)03000-9

[15] Bremner, J.D. (2006) Stress and Brain Atrophy. CNS \& Neurological Disorders-Drug Targets, 5, 503-512. https://doi.org/10.2174/187152706778559309

[16] Shishkina, G.T., Kalinina, T.S., Berezova, I.V., Bulygina, V.V. and Dygalo, N.N. (2010) Resistance to the Development of Stress-Induced Behavioral Despair in the Forced Swim Test Associated with Elevated Hippocampal Bcl-xl Expression. Behavioural Brain Research, 213, 218-224. https://doi.org/10.1016/j.bbr.2010.05.003

[17] Panaretakis, T., Pokrovskaja, K., Shoshan, M.C. and Grandér, D. (2002) Activation of Bak, Bax, and BH3-Only Proteins in the Apoptotic Response to Doxorubicin. The Journal of Biological Chemistry, 277, 44317-44326. https://doi.org/10.1074/jbc.M205273200

[18] Sun, F., Akazawa, S., Sugahara, K., Kamihira, S., Kawasaki, E., Eguchi, K. and Koji, T. (2002) Apoptosis in Normal Rat Embryo Tissues during Early Organogenesis: The Possible Involvement of Bax and Bcl-2. Archives of Histology and Cytology, 65, 145-157. https://doi.org/10.1679/aohc.65.145

[19] Li, X., Han, F., Liu, D. and Shi, Y. (2010) Changes of Bax, Bcl-2 and Apoptosis in Hippocampus in the Rat Model of Posttraumatic Stress Disorder. Neurological Research, 32, 579-586. https://doi.org/10.1179/016164110X12556180206194

[20] Li, X., Han, F. and Shi, Y. (2013) Increased Neuronal Apoptosis in Medial Prefron- 
tal Cortex Is Accompanied with Changes of Bcl-2 and Bax in a Rat Model of Post-Traumatic Stress Disorder. Journal of Molecular Neuroscience, 51, 127-137. https://doi.org/10.1007/s12031-013-9965-Z

[21] Miller, S.A., Dykes, D.D. and Polesky, H.F. (1988) A Simple Salting out Procedure for Extracting DNA from Human Nucleated Cells. Nucleic Acids Research, 16, 1215. https://doi.org/10.1093/nar/16.3.1215

[22] Bunce, M., Procter, J. and Welsh, K.I. (1999) A DNA Based Detection and Screening System for Identifying HLA Class I Expression Variants by Sequence-Specific Primers. Tissue Antigens, 53, 498-506. https://doi.org/10.1034/j.1399-0039.1999.530506.x

[23] Strasser, A., O’Conner, L. and Dixit, V.M. (2000) Apoptosis Signaling. International Journal of Cancer, 69, 217-245. https://doi.org/10.1146/annurev.biochem.69.1.217

[24] Li, X.M., Han, F., Liu, J.D. and Shi, Y. (2010) Single-Prolonged Stress Induced Mitochondrial Dependent Apoptosis in Hippocampus in the Rat Model of Post-Traumatic Stress Disorder. Journal of Chemical Neuroanatomy, 40, 248-255. https://doi.org/10.1016/j.jchemneu.2010.07.001

[25] Alani, B., Maghsoudi, N., Khatibi, A., Noureddini, M., Asefifar, F. and Shams, J. (2013) Study of the Variations in Apoptotic Factors in Hippocampus of Male Rats with Posttraumatic Stress Disorder. Advanced Biomedical Research, 2, 42. https://doi.org/10.4103/2277-9175.109757

[26] Mkrtchian, G.M., Boiadzhian, A.S., Avetian, D.G. and Sukiasian, S.G. (2013) The Involvement of Abnormal Apoptosis in the Disturbance of Synaptic Plasticity in Posttraumatic Stress Disorder. Zhurnal Nevrologii I Psikhiatrii Imeni S.S. Korsakova, 113, 26-29.

[27] Salvadore, G., Nugent, A.C., Chen, G., Akula, N., Yuan, P., Cannon, D.M., Zarate, C.A. Jr., McMahon, F.J., Manji, H.K. and Drevets, W.C. (2009) Bcl-2 Polymorphism Influences Gray Matter Volume in the Ventral Striatum in Healthy Humans. Biological Psychiatry, 66, 804-807. https://doi.org/10.1016/j.biopsych.2009.05.025

[28] Yuan, P., Baum, A.E., Zhou, R., Wang, Y., Laje, G. and McMahon, F.J. (2008) Bcl-2 Polymorphisms Associated with Mood Disorders and Antidepressant-Responsiveness Regulate Bcl-2 Gene Expression and Cellular Resilience in Human Lymphoblastoid Cell Lines. Biological Psychiatry, 63, 63S.

[29] Soeiro-de-Souza, M.G., Salvadore, G., Moreno, R.A., Otaduy, M.C., Chaim, K.T., Gattaz, W.F., Zarate, C.A. and Machado-Vieira, R. (2013) Bcl-2 rs956572 Polymorphism Is Associated with Increased Anterior Cingulate Cortical Glutamate in Euthymic Bipolar I Disorder. Neuropsychopharmacology, 38, 468-475. https://doi.org/10.1038/npp.2012.203

[30] Uemura, T., Green, M., Corson, T.W., Perova, T., Li, P.P. and Warsh, J.J. (2011) Bcl-2 SNP rs956572 Associates with Disrupted Intracellular Calcium Homeostasis in Bipolar I Disorder. Bipolar Disorder, 13, 41-51. https://doi.org/10.1111/j.1399-5618.2011.00897.x 